\title{
Low Dose Aspirin in Preeclampsia - History Revisited
}

\author{
Sonika Mann, Amit Mann, Anju Huria, Deepti.
}

\begin{abstract}
:
Objectives: To study the role of low-dose aspirin in prevention of pre-eclampsia and its effect on maternal \& neonatal outcome. DESIGN: A prospective randomized double-blind placebo controlled study. METHODS: All the high risk antenatal women presenting between 12-24 weeks of gestation were randomized to receive either aspirin $75 \mathrm{mg} /$ day or matching placebo. Both the groups were compared for pre-eclampsia, pregnancy duration, birthweight, adverse maternal or neonatal outcome. RESULTS. A total of 120 women were followed up. The incidence of pre-eclampsia in aspirin group was $0.83 \%$ , whereas none of the patients developed preeclampsia in placebo group. There were no significant differences between both the groups in. number of preterm delivery $11.47 \%$ in aspirin group vs $22 \%$ in placebo group, of SGA babies $16.9 \%$ vs $17.2 \%$ in placebo group. Aspirin was also not associated with increased risk of maternal or fetal complications. CONCLUSIONS: : The results of present study do not support the use of low dose aspirin for prevention of pre-eclampsia or its complications in any category of high risk women as proven by results of previous large scale trials and further multicentric large trials are still required to assess the role.
\end{abstract}

Key words: Aspirin, Preeclampsia, Gestational hypertension, Pregnancy

Submitted Date 13 June 2013

Accepted Date: 19 June 2013

\section{Background}

Preeclampsia affects $2 \%-3 \%$ of pregnancies and every year is responsible for 60,000 maternal deaths worldwide. ${ }^{1}$ The major goal of prenatal care at present is the early detection of onset of preeclampsia and to initiate aggressive therapy to prevent some complications in mother and the fetus. To achieve this, one must be clear about pathogenesis of a disease, however preeclampsia remains the "disease of theories", reflecting the confusion that surrounds it . ${ }^{2}$ Most authors ${ }^{3,45}$ have agreed upon the imbalance between prostacyclin, a vasodilator and inhibitor of platelet aggregation thromboxane A2 with the opposing action of vasoconstriction and promotion of platelet aggregation. The consequent platelet activation may account for some of the major clinical manifestations of preeclampsia. ${ }^{6}$ This imbalance is targeted by use of low dose aspirin in prevention of preeclampsia. This triggered the multiple historical aspirin intervention trials ${ }^{7,8,9}$ in altering the natural history of preeclampsia. Unfortunately all of them had variable results. The largest CLASP trial ${ }^{7}$ raised a theoretical possibility that the benefits of antiplatelet therapy are confined to high risk women especially if started before 20 weeks of gestation. Royal College of Obstetricians and Gynecologists recommends the need of further trials in role of aspirin ${ }^{10}$. So the present prospective study was designed to find the role of low-dose aspirin in prevention of preeclampsia and its consequences and understanding its role in pathogenesis of preeclampsia.

\section{Materials And Methods}

This was a prospective randomized double-blind placebo controlled study. A total of 170 patients were enrolled between 12-24 weeks of period of gestation for the present study between August 2004 to July 2006 in the Department of Obstetrics and Gynecology, Government Medical College and Hospital, Chandigarh. The study was approved by the Hospital Ethics Committee. All antenatal women were screened, examined and investigated. After an informed consent the women were randomly allocated to receive Aspirin $75 \mathrm{mg}$ ( group A) or starch tab (group B) once daily up to 34 weeks period of gestation. The inclusion criteria included: nulliparous women, pregnant women at extremes of age (< 20 years, > 35 years), multiple gestation, gestational diabetes mellitus / Type 1 diabetes mellitus / Type 2 diabetes mellitus, obese women (pre-pregnancy BMI >29), family history of hypertension, history of preeclampsia /eclampsia in previous pregnancy. The women who had history of hypersensitivity to aspirin, obstructive pulmonary disease, history of peptic ulcer, hepatic disease, long treatment with nonsteroidal anti-inflammatory drugs or previous history of abruption, were excluded from the study. Blood pressure was recorded on the right arm in the sitting position after a rest of half an hour using Korotkoff's phase V sounds. Ultrasound was done in every patient to confirm gestation and to rule out twins, ectopic pregnancy and hydatiform mole. At each visit medication was given in coded packages 
and the women were inquired about any side effects experienced. At every visit their blood pressure was recorded and examined for proteinuria. At the time of delivery, duration of labour and approximate blood loss was assessed and placenta examined for any apparent abnormality. APGAR scores at 1 and 5 minutes and birth weights were recorded at birth in all neonates. All babies were examined thoroughly by pediatrician in order to pick up any congenital malformations, any bleeding tendencies in the form of cephalhaematoma or intracranial bleeding or purpuras and also for the evidence of persistent pulmonary circulation. All the babies were routinely followed up to one year of age. At the end of study the data was collected and decoded. The qualitative data was represented in percentage and compared using Chisquare test. The quantitative data was represented in the form of mean+/- SD. It was compared using unpaired t-test. Changes in blood pressure were compared using Mann Whitney test. p value $<0.05$ was taken as significant.

\section{Results}

Out of 170 women, 50 were lost to follow up hence not included in the study. Only the patients satisfying inclusion criteria were included (Table 1). Both the groups had similar risk profile subjects.

The mean age of patients was $24.67 \pm 3.27$ and $24.96 \pm 3.10$ years in group A and group B respectively. The demographic characteristics in both the groups were similar. The mean age of recruitment into the study was $17.17 \pm 3.62$ (group A)and $17.13 \pm 3.46$ ( group B ) weeks of gestation. In aspirin group $8.57 \%$ developed gestational hypertension whereas in placebo group $12 \%$ patients had gestational hypertension ( $\mathrm{p}$ value $>0.05$ ). The mean blood pressures at various gestations in both the groups is shown in table 2. Preeclampsia developed in $0.83 \%$ in placebo group whereas no patient in study group had preeclampsia. ( $\mathrm{p}$ value $>0.05$ ). The difference was not statistically significant. In placebo group, 11 patients $22 \%$ ) had preterm delivery whereas in aspirin group 8 patients $(11.47 \%)$ delivered before 37 weeks. ( $\mathrm{p}$ value $>0.05$ ) Table 3. The evidence of IUGR babies was less in aspirin group $(16 \%)$ versus $21.6 \%$ in group B. The mean blood loss was same in both the groups. There was no higher incidence of cases of abruption in aspirin group as it was stopped at 34 weeks long before onset of labour. The mean birth weight of babies in aspirin group was $2.73 \pm 0.46 \mathrm{~kg}$ and $2.7 \pm 0.49 \mathrm{~kg}$ in other group. SGA(<-1 S.D) babies were $16.9 \%$ as compared to $17.2 \%$ in placebo group ( $\mathrm{p}$ value $>0.05$ ). The neonatal complications in both the groups were comparable. No evidence of any bleeding tendencies, neonatal jaundice, persistent pulmonary circulation was noted in neonates of aspirin group. Table 4. Five women in study group complained of gastritis. No other significant side effects were observed.

\section{Discussion}

The hypertensive disorders complicating pregnancy are common and form one of the great triad along with hemorrhage and sepsis that contributes to large number of maternal morbidity and mortality. ${ }^{11}$ The search for a preventive measure still remains challenging. An optimal intervention will aim at reversing the imbalance between prostacyclin and thromboxane A2. ${ }^{7}$ thus aspirin has been studied in many doses with variable results. The incidence of hypertensive disorders in general population is $6-8 \%$ whereas in our study incidence was $25 \%$ confirming the inclusion of high risk women. In the present study no difference was noted in incidence of preeclampsia among both the groups. Cochrane review analyzed all trials between 1994-2003 and their results showed a 19\% reduction in risk of preeclampsia associated with use of antiplatelet agents, $7 \%$ reduction in preterm delivery, $16 \%$ reduction in fetal deaths. ${ }^{13}$ The number of IUGR babies was same in both the groups correlating well with results of Caritis et al and Golding $\mathrm{J}^{8,14}$. Though there was trend toward less number of preterm deliveries in aspirin group (11.42\%) than placebo group $(22 \%)$ but this difference was statistically not significant may be because the number of subjects were less. This was in accordance with results of other studies. ${ }^{7,14}$ There were no apparent major complications noted in pregnant women and babies due to aspirin in our study.

\section{Conclusions}

Despite the high risk population studied in our study, the results appear to be much less promising similarly as shown by large trials till date. The discrepancy in success of small scale trials ${ }^{15,16}$ and failure of large scale trials ${ }^{7,8,17}$ may be due to publication bias, with projection more on positive trials than with trials showing unpromising results. ${ }^{18,19}$ Based on the average risk of women included in these trials, about 70 women would have to be treated to prevent one case of pre-eclampsia, and 240 to prevent one baby death, ${ }^{20}$ warranting the need of further multicentre trials involving large number of women. Hence further studies are required as there is still much to be established in the role of aspirin with emphasis on studies with negative results also. 


\section{References}

[1]. Poston L, Briley A, Seed P, Kelly F, Shennan A. Vitamin C and vitamin E in pregnant women at risk for pre-eclampsia (VIP trial):Randomised placebo-controlled trial. The Lancet 2006;367(9517):1145-54.

[2]. Robert JM, Cooper DW. Pathogenesis and genetics of preeclampsia. Lancet 2001;357:53-56.

[3]. De Wolf F, Robertson WB, Brosens I. The ultrastructure of acute atherosis in hypertensive pregnancy. Am J Obstet Gynecol 1975;123: 164-74.

[4]. Khong TY, De Wolf F, Robertson WB, et al. Inadequate maternal vascular response to placentation in pregnancies complicated by pre-eclampsia and by small-for-gestational age infants. Br J Obstet Gynaecol 1986;93:1049-59.

[5]. Walsh SW: Preeclampsia - An imbalance of placental prostacyclin and thromboxane production. Am J Obstet Gynecol 1985;152:335-40.

[6]. Redman CWG. Platelets and the beginnings of pre-eclampsia. N Engl J Med 1990;323:478-80.

[7]. CLASP: A randomized trial of low dose aspirin for the prevention and treatment of preeclampsia among 9364 pregnant women (collaborative low dose aspirin study in pregnancy). The Lancet 1994;343:619-29

[8]. Caritis S, Sibai B, Hauth J, et al and NICHD (National Institute Child Health and Human Development Network)Low dose aspirin to prevent preeclampsia in women at high risk. N Engl J Med 1998;338(11):701-05.

[9]. Sibai BM, Gariti SN, Thom E, et al. Prevention of preeclampsia with low dose aspirin in healthy nulliparous pregnant women. N Engl Med J 1993;329:1213-18

[10]. Royal College of Obstetricians and Gynaecologists. Preeclampsia-study group recommendations. Sept 3;page 2.

[11]. Cunningham FG, Leveno KJ, Bloom SL, et al. Williams Obstetrics $22^{\text {nd }}$ ed. $2005 ; 61$.

[12]. National High Blood pressure Education Program: Working Group Report on High Blood Pressure in Pregnancy. Am J Obstet Gynecol 2000;183(1):S1-S22.

[13]. Duley L, Henderson - Smart D J, Knight M, King J F. Antiplatelet agents for preventing preeclampsia and its complications. Cochrane Database Syst Rev. 2004;(1):CD004659.

[14]. Golding J. A randomized trial of low dose aspirin for primiparae in pregnancy. The Jamaica Low Dose Aspirin Study Group. Br J Obstet Gynaecol 1998;105:293-9.

[15]. Schiff E, Peleg E, Goldenberg M, et al. The use of Aspirin to prevent pregnancy induced hypertension and lower the ratio of thromboxane $A_{2}$ to prostacyclin in relatively high risk pregnancies. N Engl J Med 1989; 321:351-56.

[16]. McParland P, Pearce JM, Chamberlain GVP. Doppler ultrasound and aspirin in recognition and prevention of pregnancy induced hypertension. The Lancet 1990;335:1552-55.

[17]. Parrazani F, Beneletto C, Frusca T. Italian study of Aspirin in pregnancy. Low dose aspirin in prevention and treatment of intrauterine growth retardation and pregnancy induced hypertension. The lancet 1993;341:396-99.

[18]. Benigni A, Gregorini G, Frusca J, et al. Effect of low dose aspirin on fetal and maternal generation of thromboxane by platelets in women at risk for pregnancy induced hypertension. N Engl J Med 1989;321:357-62.

[19]. Hauth JC, Goldenberg RL, Parker CR, et al. Low dose aspirin therapy to prevent preeclampsia. Am J Obstet Gynecol 1993;168:1083-93.

[20]. The Perinatal Antiplatelet Review of International Studies (PARIS) Collaboration Steering Group. Antiplatelet agents for prevention of pre-eclampsia and its consequences: a systematic review and individual patient data meta-analysis. BMC Pregnancy Childbirth. 2005; 5: 7 